\title{
Características da produção leiteira da região do agreste do estado de Pernambuco, Brasil
}

\section{Characteristics of the milk production of the agreste region of the state of Pernambuco, Brazil}

\author{
Alexandre Amorim Monteiro ${ }^{1}$; Ronaldo Tamanini ${ }^{1}$; Livia Cavaletti Corrêa da Silva ${ }^{1}$; \\ Marcos Rodrigues de Mattos ${ }^{1}$; Douglas Furtado Magnani²; Loredana d'Ovidio ${ }^{3}$; \\ Luis Augusto Nero ${ }^{4}$; Márcia de Aguiar Ferreira Barros ${ }^{5}$; \\ Edleide Maria Freitas Pires ${ }^{6}$; Benoit Pascal Dominique Paquereau ${ }^{7}$; Vanerli Beloti ${ }^{8^{*}}$
}

\section{Resumo}

O Agreste pernambucano é caracterizado por uma economia diversificada, com diferentes cultivos, além da pecuária de leite e de corte. Em 2004 o Estado produziu 398 milhões de litros de leite, o que representou $14,7 \%$ da produção da Região Nordeste e 1,7\% da produção Nacional. Este trabalho teve como objetivo caracterizar as propriedades leiteiras da região Agreste do Estado de Pernambuco, observando condições e fatores que pudessem interferir na qualidade do leite. Foram selecionadas 41 propriedades leiteiras da região. Observou-se o predomínio das propriedades de pequeno porte, com até $25(43,9 \%)$ animais em lactação, sendo ordenha manual em $36(87,8 \%)$ das propriedades. Em relação às práticas de higiene na ordenha, $16(39,0 \%)$ dos produtores lavavam os tetos antes da ordenha, mas apenas $4(9,8 \%)$ realizavam pré-dipping e $34(82,9 \%)$ ordenhavam na presença do bezerro. Apenas $5(12 \%)$ das propriedades realizavam algum tipo de tratamento da água utilizada para higienização de instalações e equipamentos, mesmo a água para consumo humano era tratada em apenas $43,9 \%$ das propriedades. A refrigeração do leite era realizada por $10(24,4 \%)$ propriedades em tanques comunitários. Quanto a sanidade do rebanho 39 $(95,1 \%)$ proprietários realizavam vacinação para febre aftosa e $23(56,1 \%)$ para brucelose, enquanto 10 $(24,4 \%)$ realizavam teste para tuberculose. As condições de produção se revelaram precárias quanto às estruturas nas propriedades, mostrando a necessidade da melhoria das instalações e manejo dos animais e, principalmente, a implantação de Boas Práticas na ordenha, adequadas à realidade local.

Palavras-chave: Leite, produção leiteira, região agreste

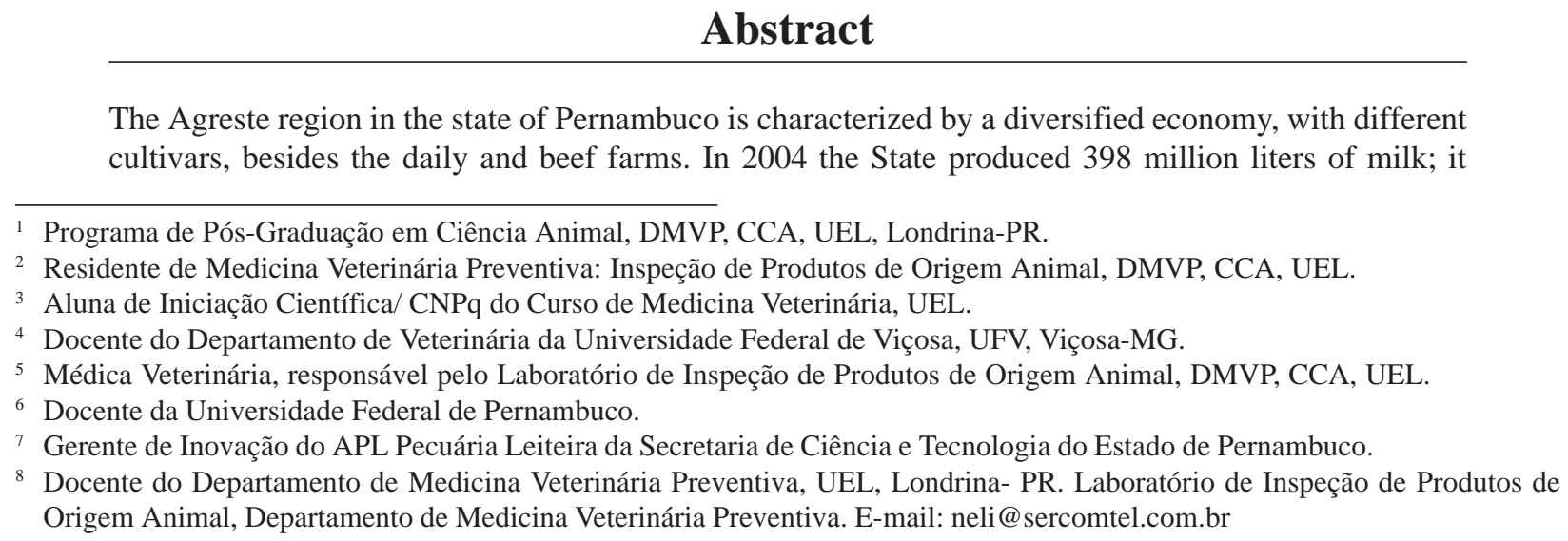

The Agreste region in the state of Pernambuco is characterized by a diversified economy, with different cultivars, besides the daily and beef farms. In 2004 the State produced 398 million liters of milk; it

1 Programa de Pós-Graduação em Ciência Animal, DMVP, CCA, UEL, Londrina-PR.

2 Residente de Medicina Veterinária Preventiva: Inspeção de Produtos de Origem Animal, DMVP, CCA, UEL.

3 Aluna de Iniciação Científica/ CNPq do Curso de Medicina Veterinária, UEL.

4 Docente do Departamento de Veterinária da Universidade Federal de Viçosa, UFV, Viçosa-MG.

5 Médica Veterinária, responsável pelo Laboratório de Inspeção de Produtos de Origem Animal, DMVP, CCA, UEL.

6 Docente da Universidade Federal de Pernambuco.

7 Gerente de Inovação do APL Pecuária Leiteira da Secretaria de Ciência e Tecnologia do Estado de Pernambuco.

8 Docente do Departamento de Medicina Veterinária Preventiva, UEL, Londrina- PR. Laboratório de Inspeção de Produtos de Origem Animal, Departamento de Medicina Veterinária Preventiva. E-mail: neli@ sercomtel.com.br

* Autor para correspondência 
represented $14.7 \%$ of the Northeast Region production and $1.7 \%$ of the National production. The aim of this work was to characterize the milk properties of the Agreste region of Pernambuco, observing conditions and factors that could interfere with milk quality. In the survey, 41 milk farms were selected in the region. Small milk farms were the most common found, with less than 25 (43.9\%) animals in lactation, and $36(87.8 \%)$ farms held a manual milking process. In relation to hygiene practices during milking, 16 $(39.0 \%)$ of the producers washed the teats before beginning, but only $4(9.8 \%)$ performed pre-dipping and $34(82.9 \%)$ milked in the presence the calf. Only $5(12 \%)$ farms applied some treatment to the water used for cleaning installations and equipment, even the water for human consumption was treated in only $43.9 \%$ of the farms. Milk refrigeration was performed in $10(24.4 \%)$ farms in communitarian tanks. As far as animal health is concerned, $39(95.1 \%)$ owners vaccinated for food and mouth disease and 23 $(56.1 \%)$ for brucellosis, while $10(24.4 \%)$ tested for tuberculosis. Regarding the farms structure the production conditions were precarious, showing the need of improving the structure itself and animal handling. As well as the implementation of Good Manufacturing Practices in the milking process, proper to the local reality.

Key words: Milk, milk production, wasteland region

\section{Introdução}

O Agreste de Pernambuco é a região intermediária entre a Zona da Mata e o Sertão (Figura 1) e é caracterizada por uma economia diversificada, com o cultivo de lavouras como milho, feijão e mandioca (entre outras), além da pecuária de leite e de corte. Dados recentes revelam que nos últimos dois anos a produção leiteira dessa região cresceu $23 \%$, representando $73 \%$ da produção leiteira do Estado de Pernambuco (CONSELHO NACIONAL E ABASTECIMENTO, 2004; FIGUEIROA, 2006).

Em dezembro de 2000 o Governo do Estado de
Pernambuco em parceria com o Governo Federal, em associação com a Secretaria de Produção Rural e Reforma Agrária (SPRRA) e a Companhia de Abastecimento e de Armazéns Gerais do Estado de Pernambuco (CEAGEPE), lançou o Programa Leite de Pernambuco, com o principal objetivo de fornecer leite a famílias carentes, especialmente crianças, gestantes e lactantes. Ainda, esse programa impulsionou a cadeia produtiva leiteira, incentivando a produção local e favorecendo principalmente as regiões do Agreste, Zona da Mata e Metropolitana do Recife (SECRETÁRIA DE PRODUÇÃO RURAL E REFORMA AGRÁRIA, 2006).

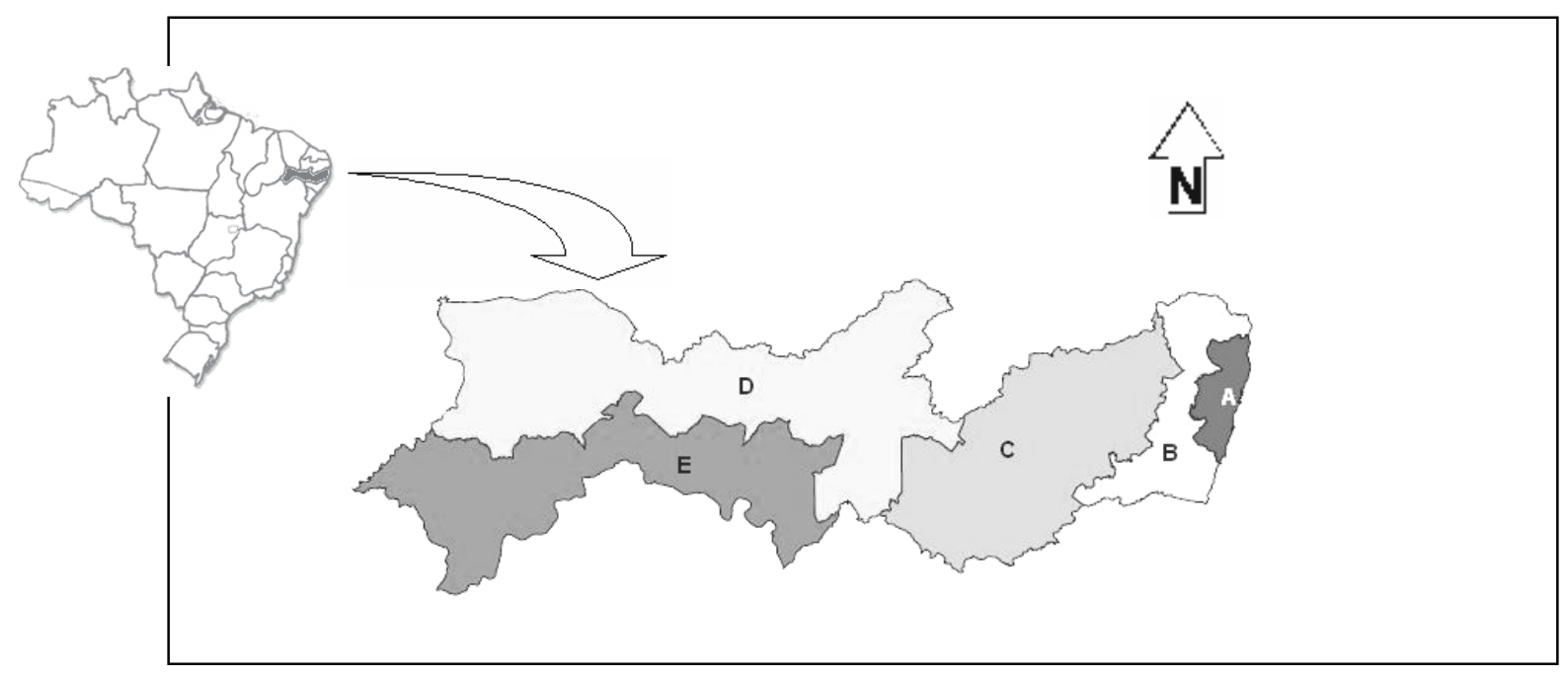

Figura 1. Regiões geográficas do Estado de Pernambuco, Brasil. A: Região Metropolitana de Recife, B: Zona da Mata, C: Agreste, D: Sertão, E: São Francisco. 
Entre 2000 e 2004 a produção leiteira do Estado de Pernambuco mostrou crescimento (Figura 2). Dados da produção leiteira do Brasil mostram que em 2004 o Estado produziu 398 milhões de litros de leite, o que representou $14,7 \%$ da produção da Região Nordeste e $1,7 \%$ da produção Nacional (INSTITUTO BRASILEIRO DE GEOGRAFIA E ESTATÍSTICA, 2006). Essa produção colocou o Estado como segundo maior produtor da região Nordeste e 12 do Brasil. Atualmente em Pernambuco, cerca de 14 mil pequenos e médios produtores estão na atividade leiteira, concentrados principalmente na região do Agreste (73\% da produção do Estado), e geram uma produção diária de 980 mil litros (INSTITUTO BRASILEIRO DE GEOGRAFIA E ESTATÍSTICA, 2006; SECRETÁRIA DE PRODUÇÃO RURAL E REFORMA AGRÁRIA, 2006; CONSELHO NACIONAL E ABASTECIMENTO, 2004).

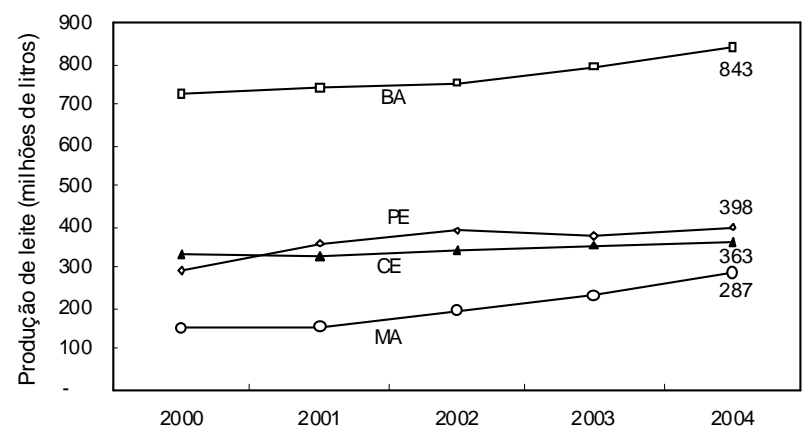

Figura 2. Evolução da produção leiteira nos 04 Estados (BA- Bahia, PE- Pernambuco, CE-Ceará, MA- Maranhão) com maior produção na Região Nordeste do Brasil, entre 2000 e 2004 (INSTITUTO BRASILEIRO DE GEOGRAFIA EESTATÍSTICA, 2006).

No Brasil, de modo geral, o leite é obtido sob condições higiênico-sanitárias deficientes e, em conseqüência, apresenta baixa qualidade microbiológica, constituindo um risco à saúde da população quando consumido sem tratamento térmico, situação comum na região Nordeste (MARTINS; ALBUQUERQUE, 1999; CATÃO; CEBALLOS, 2001; PADILHA et al., 2001). A baixa qualidade do produto pode ser atribuída a deficiências no manejo e higiene de ordenha, manutenção e desinfecção inadequada dos equipamentos, refrigeração ineficiente ou inexistente e mão de obra desqualificada (NELSON, 1992). Assim, cuidados higiênicos para evitar a contaminação do leite devem ser tomados desde a ordenha até o produto final (SANTANA et al., 2004; CATÃO; CEBALLOS, 2001), por meio das Boas Práticas de Produção e Fabricação.

Outra característica bastante marcante da produção leiteira no Brasil é o predomínio de pequenas e médias propriedades com características de agricultura familiar, onde geralmente essa atividade é a principal fonte de renda. A falta de informação, assistência e investimentos na produção leiteira geram baixas produtividade e qualidade do produto. Pode-se observar que propriedades com maior produção leiteira frequentemente produzem leite de melhor qualidade, quando comparadas àquelas com menor produção (TKAEZ et al., 2004).

Há diferenças de qualidade no leite produzido pelos diferentes Estados brasileiros, que podem ser atribuídas às condições encontradas em cada região, como perfil do produtor, maior acesso à assistência técnica, presença de órgãos extensionistas e programas regionais de controle sanitário de rebanhos e principalmente laticínios com políticas de pagamento por qualidade.

Este trabalho teve como objetivo caracterizar as propriedades leiteiras da região Agreste do Estado de Pernambuco, observando condições de produção e fatores que pudessem interferir na qualidade do leite, como manejo, instalações, utilização de Boas Práticas de produção e aspectos correlacionados.

\section{Material e Métodos}

Foram selecionadas 41 propriedades produtoras de leite de um total de 400 (INSTITUTO BRASILEIRO DE GEOGRAFIA E ESTATÍSTICA, 2006) do Agreste meridional de Pernambuco, por indicação da Secretaria de Produção Rural e Reforma Agrária (SPRRA) do Estado de Pernambuco e da 
Cooperativa dos Produtores de Leite e Derivados de Pernambuco (COOPROL), de forma que representassem o perfil da produção regional. Aspectos de produção, condições das instalações, características de manejo, utilização de Boas Práticas de Produção, refrigeração do leite e outros aspectos como sanidade animal e origem da água para uso humano e para lavagem de instalações e equipamentos de ordenha foram levantados através de questionário aplicado aos produtores (Apêndice 1), entre junho e outubro de 2005.

Para tratamento estatístico foram utilizados os programas Microsoft Office Excel 2003 e STATISTICA versão 6.0, 2001.

\section{Resultados e Discussão}

\section{Características de instalações}

Com relação à estrutura física das propriedades estudadas, observou-se que a maioria apresentava condições que foram consideradas como deficientes, sem instalações básicas ou com instalações mal planejadas, frequentemente estábulos que geravam grandes dificuldades na higienização. Conseqüência desse perfil foi a alta freqüência de acúmulo de lama e fezes dos animais nos locais de ordenha. Em 23 $(56,1 \%)$ propriedades, a ordenha era realizada em um estábulo de chão batido ou de concreto (Figura 3). Durante a ordenha, condições inadequadas de produção e higiene comprometem a qualidade do leite, já que sujidades, microrganismos e substâncias químicas, presentes no próprio local de ordenha, podem ser imediatamente incorporados ao produto (OLIVEIRA; FONSECA; GERMANO, 1999).

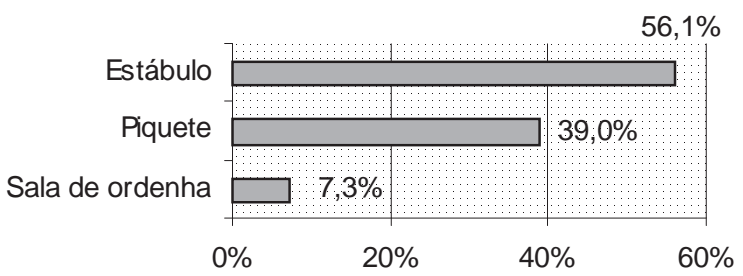

Figura 3. Tipos de instalações de ordenha observadas em 41 propriedades leiteiras, localizadas na região do Agreste do Estado de Pernambuco, Brasil, entre junho e outubro de 2005.

\section{Características de animais e manejo}

Em 39 (95,1\%) propriedades, verificou-se um predomínio de animais mestiços compondo o rebanho. Em $30(73,2 \%)$ propriedades a ordenha era realizada duas vezes ao dia, sendo mais freqüente a ordenha manual com bezerro ao pé, observada em 34 (82,9\%) das propriedades visitadas (Figura 4). No processo de ordenha manual a falta de higiene adequada, principalmente de tetos e das mãos dos ordenhadores, favorece a contaminação do leite. O manejo de ordenha é uma das estratégias mais importantes para garantir a qualidade do leite produzido (FONSECA; SANTOS, 2000).

Em relação à alimentação dos animais, 39 (97,5\%) propriedades forneciam volumoso, principalmente palma forrageira (Opuntia ficus-indica), 35 (87,5\%) concentrado e $18(45,0 \%)$ sal mineral para os animais. A alimentação dos animais tem relação com a qualidade e composição do leite, sendo um importante fator na produção leiteira (OLIVEIRA; FONSECA; GERMANO, 1999).

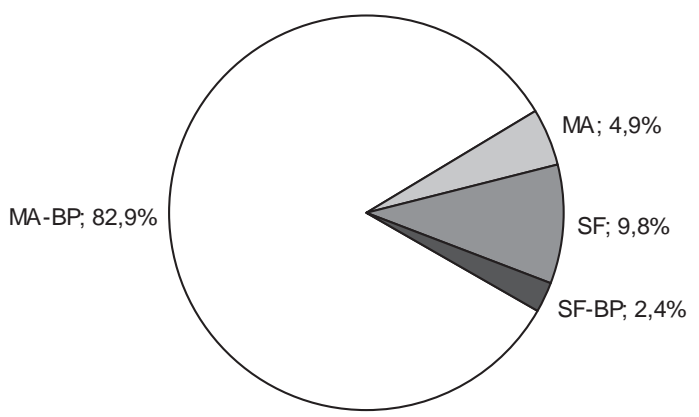

MA-BP - Manual (bezerro ao pé)

MA - Manual

SF - Mecânica (sistema semi-fechado)

SF-BP - Mecânica (sistema semi-fechado, bezerro ao pé)

Figura 4. Tipos de ordenhas observados nas 41 propriedades leiteiras, localizadas na região do Agreste do Estado de Pernambuco, Brasil, entre junho e outubro de 2005 . 


\section{Dados da produção}

Em relação ao número de animais por propriedade, a média foi de 49 animais, sendo os menores produtores $(70,7 \%)$ classificados como aqueles com até 50 animais e os maiores $(7,3 \%)$ como aqueles com mais de 100. Quanto ao número de animais em lactação, a média foi de 26 animais. Observando-se um predomínio das propriedades de pequeno porte, com até 25 animais em lactação $(43,9 \%)$.
De acordo com as informações dos produtores, estimou-se a produção média diária geral em 226,8 litros/dia, sendo mais freqüente as propriedades que produzem de 50 a 200 litros/dia (48,8\%). Também se observou que as médias de produção por animal são maiores nas propriedades que há maior número de animais (Tabela 1).

Tabela 1. Classificação das 41 propriedades leiteiras do Agreste do Estado de Pernambuco, Brasil, quanto ao número de animais, número de animais em lactação e médias de produção leiteira.

\begin{tabular}{lllcc}
\hline $\begin{array}{c}\text { Número de } \\
\text { animais na } \\
\text { Propriedade }\end{array}$ & \multicolumn{1}{c}{$\begin{array}{c}\text { Animais em } \\
\text { lactação }\end{array}$} & $\begin{array}{c}\text { Número de } \\
\text { Propriedades (\%) }\end{array}$ & $\begin{array}{c}\text { Média diária de } \\
\text { produção de leite } \\
\text { (litros) }\end{array}$ & $\begin{array}{c}\text { Média diária de } \\
\text { produção por animal } \\
\text { (litros) }\end{array}$ \\
\hline \multirow{2}{*}{ Até 50} & até 25 & $18(43,9)$ & 73,8 & 7,6 \\
& Mais que 25 & $11(26,8)$ & 219,1 & 6,6 \\
& Sub-Total & $29(70,7)$ & 128,9 & 7,2 \\
$50-100$ & até 50 & $5(12,2)$ & 172,0 & 8,8 \\
& Mais que 50 & $4(09,8)$ & 762,5 & 11,6 \\
& Sub-Total & $9(22,0)$ & 434,4 & 10,0 \\
Mais que 100 & até 50 & $1(02,4)$ & & 10,4 \\
& Mais que 50 & $2(04,9)$ & 250,0 & 11,2 \\
& Sub-Total & $3(07,3)$ & 700,0 & 10,9 \\
\hline & Total & $41(100,0)$ & 550,0 & 8,1 \\
\hline
\end{tabular}

\section{Utilização de boas práticas e resfriamento}

Em relação às práticas de higiene adotadas na ordenha, $27(65,9 \%)$ produtores utilizavam alguma prática de higienização no momento da ordenha. Verificou-se que $16(39,0 \%)$ realizavam a lavagem dos tetos, $11(26,8 \%)$ desprezavam os três primeiros jatos de leite, $10(24,4 \%)$ usavam caneca telada como prática rotineira, $09(22,0 \%)$ filtravam o leite ao passar para o latão, $05(12,2 \%)$ realizavam pósdipping e $04(9,8 \%)$ pré-dipping sendo a prática menos utilizada. Em $30(73,2 \%)$ propriedades não era realizada a prática de desprezar os três primeiros jatos antes da ordenha, já que na maioria a ordenha era com bezerro ao pé (figura 5).

Quanto à refrigeração do leite após a ordenha, $10(24,4 \%)$ propriedades utilizavam tanque de expansão comunitário e o restante, $31(75,6 \%)$ propriedades, não utilizavam nenhuma outra forma de conservação térmica do leite, entregando o leite em temperatura ambiente aos laticínios. A relação tempo-temperatura assume destacada relevância para conservação do leite recém-ordenhado. A redução no tempo entre a produção e a pasteurização, e a manutenção do leite em baixas 
temperaturas, podem ajudar a controlar a qualidade do leite cru. (FONSECA; SANTOS, 2000; FONSECA; SANTOS, 2001; SANTANA et al., 2004).

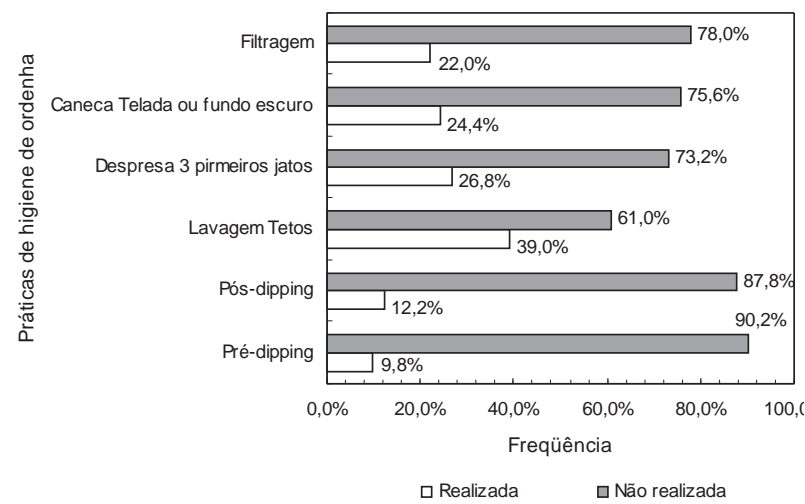

Figura 5. Freqüências de utilização de práticas de higienização na ordenha, em 41 propriedades leiteiras, localizadas na região do Agreste do Estado de Pernambuco, Brasil, entre junho e outubro de 2005.

\section{Sanidade animal}

Em relação à prevenção de enfermidades nos animais, os proprietários foram questionados quanto à realização de testes para tuberculose e brucelose, além de vacinações contra brucelose e febre aftosa. $10(24,4 \%)$ produtores afirmaram realizar teste para tuberculose e $14(34,1 \%)$ para brucelose. Em relação às vacinações, $39(95,1 \%)$ declararam que realizavam vacinação para febre aftosa e $23(56,1 \%)$ para brucelose (Tabela 2). A tuberculose e a brucelose possuem fundamental importância para a saúde pública, uma vez que são zoonoses e é observado na região o consumo de leite cru e seus derivados (CATÃO; CEBALLOS, 2001). Por essa razão, a aplicação de tratamentos térmicos, como a pasteurização, é essencial para garantir segurança alimentar do leite e seus derivados. Essas enfermidades também interferem na capacidade plena de produção leiteira, causando reduções de até $25 \%$ na produtividade animal (POLETTO et al., 2004).
Tabela 2. Freqüência de realização da vacinação e testes para febre aftosa, tuberculose e brucelose, em 41 propriedades leiteiras, localizadas na região do Agreste do Estado de Pernambuco, Brasil, entre junho e outubro de 2005 .

\begin{tabular}{llll}
\hline \multicolumn{2}{l}{ Aspectos questionados } & Sim & Não \\
& Vacina para Febre Aftosa & $95 \%$ & $5 \%$ \\
Vacinação & Vacina para Brucelose & $56 \%$ & $44 \%$ \\
& Faz teste para Tuberculose & $24 \%$ & $76 \%$ \\
Testes & Faz teste para Brucelose & $34 \%$ & $66 \%$ \\
& & & \\
\hline
\end{tabular}

Apenas $16(39,0 \%)$ produtores afirmaram realizar tratamento de mastites dos animais em lactação, sendo que 09 (56,3\%) faziam o descarte apenas do leite dos quartos em tratamento, $06(37,5 \%)$ descartavam todo o leite e apenas $01(6,3 \%)$ afirmou não descartar o leite mesmo dos quartos tratados com antibiótico (Figura 6). Deve-se enfatizar que qualquer antibiótico utilizado em vacas em lactação, por qualquer via de administração, pode resultar em resíduos no leite. O descarte do leite deve ser realizado durante o período de carência indicado para cada medicamento utilizado, sendo recomendado o descarte total do leite de animais em tratamento (FONSECA; SANTOS, 2000).

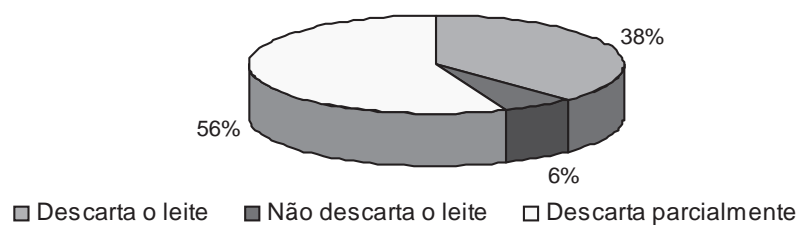

Figura 6. Destino do leite de animais em tratamento com antibióticos, em 41 propriedades leiteiras, localizadas na região do Agreste do Estado de Pernambuco, Brasil, entre junho e outubro de 2005. 


\section{Origem da água}

$\mathrm{Na}$ avaliação da origem da água utilizada para consumo humano e para higienização de instalações e equipamentos foi observada uma grande diversidade. Para a higienização, os açudes eram a fonte mais freqüente de água e a utilização se dava sem qualquer tratamento. Para o consumo humano, as principais fontes eram minas, água comercial (adquirida envasada ou a granel) e cisternas (Tabela 03). A água tem grande importância na cadeia produtiva do leite, sendo importante que sua origem ofereça qualidade para utilização na pecuária leiteira (POLEGATO; AMARAL, 2005), ou algum tratamento lhe confira esta qualidade.

Tabela 3. Origem da água utilizada para higienização de instalações e equipamentos e consumo humano, em 41 propriedades leiteiras, localizadas na região do Agreste do Estado de Pernambuco, Brasil, entre junho e outubro de 2005.

\begin{tabular}{lll}
\hline Origem & $\begin{array}{c}\text { Higienização de } \\
\text { instalações e } \\
\text { equipamentos }\end{array}$ & $\begin{array}{c}\text { Consumo } \\
\text { humano }\end{array}$ \\
\hline Açude & $14(34,1)$ & $01(02,4)$ \\
Riachos, rios & $08(19,5)$ & $01(02,4)$ \\
Barragem & $05(12,2)$ & $00(0,0)$ \\
Mina & $05(12,2)$ & $06(14,6)$ \\
Poço & $03(07,3)$ & $04(9,8)$ \\
Rede de Água & $02(04,9)$ & $03(7,3)$ \\
Cisterna & $01(02,4)$ & $06(14,6)$ \\
Lagoa & $01(02,4)$ & $00(0,0)$ \\
Água Comercial* & $00(0,0)$ & $06(14,6)$ \\
Outros & $02(04,9)$ & $14(34,1)$ \\
\hline
\end{tabular}

* Adquirida envasada ou a granel

Deve-se ressaltar que apenas $5(12 \%)$ das propriedades realizavam algum tipo de tratamento da água utilizada para higienização de instalações e equipamentos, e 43,9\% da água utilizada para consumo humano (Figura 7). A situação crítica do sistema de abastecimento do Estado de Pernambuco favorece as condições inadequadas de utilização da água. Mesmo na capital, apenas $27 \%$ da Região Metropolitana do Recife tem água encanada e esgoto tratado, sendo freqüentes as crises de falta de água, mesmo quando não ocorrem períodos prolongados de seca. No Agreste de Pernambuco a carência de água é devido à intermitência dos cursos de água (SILVA; SALGUEIRO, 2001; SECRETARIA DE CIÊNCIA TECNOLOGIA E MEIO AMBIENTE DO ESTADO DE PERNAMBUCO, 2006) e falta de rede de abastecimento, gerando freqüentes colapsos no abastecimento de água.

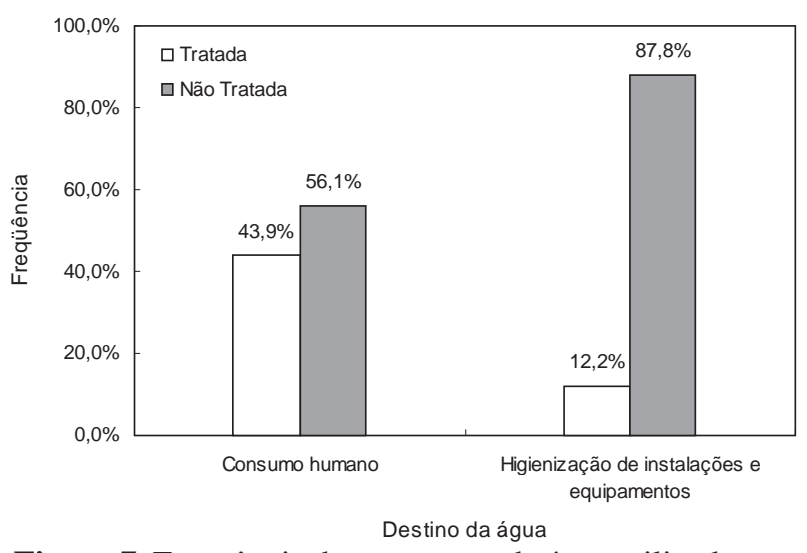

Figura 7. Freqüência de tratamento da água utilizada para consumo humano e higienização de instalações e equipamentos, em 41 propriedades leiteiras, localizadas na região do Agreste do Estado de Pernambuco, Brasil, entre junho e outubro de 2005.

\section{Conclusão}

A produção leiteira da região Agreste de Pernambuco demonstra ser emergente e tem se consolidado. Contudo, as condições de produção das propriedades se revelaram precárias, mostrando a necessidade da melhoria das (condições de) instalações e manejo dos animais, e principalmente uma assistência eficiente em relação à sanidade animal e Boas Práticas na ordenha, bem como da melhoria do sistema de abastecimento de água da região.

Devido às condições de produção leiteira encontradas, é importante a realização de estudos que avaliem as conseqüências para qualidade do leite produzido na região do Agreste do Estado de Pernambuco, abrangendo aspectos microbiológicos, 


\section{APENDICE 1 \\ Questionário \\ HOSPITAL VETERINÁRIO \\ DEPARTAMENTO DE MEDICINA VETERINÁRIA PREVENTIVA \\ LABORATÓRIO DE INSPEÇÃO DE PRODUTOS DE ORIGEM ANIMAL \\ QUESTIONÁRIO DE ORIGEM DA AMOSTRA}

\section{I) Identificação}

$\mathrm{N}^{\mathrm{o}}$ da amostra:

Identificação da Propriedade:

Identificação do Proprietário:

Endereço:

Local de produção:

Local de colheita:

Tipo:___ Data colheita:

Hora ordenha:

Hora colheita:

Temperatura da amostra:

\section{II) Dados da produção:}

Numero de animais da propriedade:

Raça:

Numero de animais em lactação:

Volume diário:

\section{III) Manejo}

1) Tipo de ordenha:

( ) Manual

( ) Mecânica

( ) Com bezerro ao pé

( ) Sem bezerro ao pé

( ) Circuito fechado

( )Circuito semi-fechado

( ) Com bezerro ao pé

( ) Sem bezerro ao pé
2) Práticas de higienização:

( ) Sim

( ) Não

( ) Pré-dipping

( ) Pós-dipping

( ) Lavagem tetos

( ) Despreza os 3 primeiros jatos

( ) Filtragem do leite

3) Número de ordenhas:
4)Instalações:
( ) Estábulo
( ) Sala de ordenha
( ) Outros:

5) Resfriamento:

( ) Tanque de imersão

( ) Tanque de expansão

( ) Tanque de expansão comunitário

( ) Outros: 
6) Alimentação:

( ) Volumoso:

( ) Concentrado:

( ) Sal mineral:

( ) Cama de frango

\section{IV)Abastecimento de água:}

Água de consumo dos animais:

1) Origem:

2) Tratamento:

( ) $\mathrm{Sim}$

( ) Não

Água de consumo humano:

1) Origem:

2) Tratamento:

( ) Sim

( ) Não

\section{V) Sanidade animal:}

1) Vacinação

( ) vacina para febre aftosa

( ) Vacina para brucelose

( ) Prática teste brucelose

( ) Prática teste tuberculose

2) Tratamentos em vacas em lactação com antibióticos: ( ) sim ( ) não

( ) descarta

( ) descarte parcial

( ) não descarta 
físico-químicos e resíduos de substâncias químicas (como pesticidas e antibióticos), que possam levar ao estabelecimento de medidas e programas para a melhoria da qualidade da produção leiteira.

\section{Agradecimentos}

A Financiadora de Estudos e Projetos (FINEP/ MDS). Esta pesquisa faz parte do Projeto "Produção de leite com qualidade e segurança a partir da implantação de boas práticas na produção leiteira na região de Recife, Pernambuco", financiado por este órgão.

\section{Referências}

CATÃO, R. M. R.; CEBALLOS, B. S. O. Listeria spp., coliformes totais e fecais e E.Coli no leite cru e pasteurizado de uma indústria de laticínios, no Estado da Paraíba (Brasil).Ciência e Tecnologia de Alimentos, Campinas, v.21, n.3, p.281-287, set./dez. 2001.

CONSELHO NACIONAL DE ABASTECIMENTO. Conjuntura Regional Pernambuco. 2004. Disponível em: <http:/www.conab.gov.br/download/sureg/PE/ conjuntura01.pdf.>. Acesso em: 18 fev. 2006.

FIGUEIROA, J. G. $O$ sinal verde para a reestruturação da agroindústria do leite no agreste. Disponível em: <http: / www.agronline.com.br/ artigos/ artigos.php?id=240>. Acesso em: 18 fev. 2006.

FONSECA, L. F. L.; SANTOS, M. V. Importância e efeito das bactérias psicrotróficas sobre a qualidade do leite. Higiene Alimentar, São Paulo, v.15, n.82, p.13-19, 2001.

FONSECA, L. F. L.; SANTOS, M. V. Qualidade do leite e controle de mastite. São Paulo: Lemos, 2000.

INSTITUTO BRASILEIRO DE GEOGRAFIA E ESTATÍSTICA. Sistema IBGE de recuperação de automática: SIDRA. Disponível em: <http:// www.sidra.ibge.gov.br >. Acesso em: 02 fev. 2006.

MARTINS, S. C. S.; ALBUQUERQUE, L. M. B. Qualidade do leite pasteurizado tipo $\mathrm{C}$ comercializado no município de Fortaleza. Bactérias multiresistentes a antibióticos. Higiene Alimentar, São Paulo, v.13, n.59, p.39-42, jan./fev. 1999.

NELSON, J. H. An overview of good manufacturing pratice-1. Bulletin of the International Dairy Federation, Brussels, v.276, p.10-11, 1992.
OLIVEIRA, C. A. F.; FONSECA, L. F. L.; GERMANO, P. M. L. Aspectos relacionados à produção, que influenciam a qualidade do leite. Higiene Alimentar, São Paulo, v.13, n.62, p.10-16, jun. 1999.

PADILHA, M. R. F.; FERNANDES, Z. F.; LEAL, T. C. A.; LEAL, N. C.; ALMEIDA, A. M. P. Pesquisa de bactérias patogênicas em leite pasteurizado tipo $\mathrm{C}$ comercializado na cidade do Recife, Pernambuco, Brasil. Sociedade Brasileira de Medicina Tropical, Uberaba, v.34, n.2, p.167171, mar./abr. 2001.

POLEGATO, E. P. S.; AMARAL, L. A. A qualidade da água na cadeia produtiva do leite: Nível de conhecimento do produtor rural. Higiene Alimentar, São Paulo, v.19, n.129, p.15-24, mar. 2005.

POLETTO, R.; KREUTZ, L. C.; GONZALES, J. C.; BARCELLOS, L. J. G. Prevalência de tuberculose, brucelose e infecções víricas em bovinos leiteiros do município de Passo Fundo, RS. Ciência Rural, Santa Maria, v.34, n.2, p.595-598, mar./abr. 2004.

SANTANA, E. H. W.; BELOTI, V.; MÜLLER, E. E.; FERREIRA, M. A.; MORAES, L. B.; PEREIRA, M. S.; GUSMÃO, V. V. Milk contamination in different points of the dairy process. II -Psychotrophics and proteolytics microorganisms. Semina: ciências agrárias, Londrina, v.25, n.4, p.349-358, 2004.

SECRETARIA DE CIÊNCIA TECNOLOGIA E MEIO AMBIENTE DO ESTADO DE PERNAMBUCO. O plano de aproveitamento dos recursos hídricos da RMR, Zona da Mata e Agreste Pernambucano I: diagnóstico dos recursos hídricos. Disponível em: <http: // www.sectma.pe.gov.br/ download/ PARHI_Diagnostico_dos_Recursos_Hidricos.pdf.>. Acesso em: 05 fev. 2006.

SILVA, E. F.; SALGUEIRO, A. A. Avaliação da qualidade bacteriológica de água de poços na região metropolitana de Recife-PE. Higiene Alimentar, São Paulo, v.15, n.90/91, p.73-78, 2001.

SECRETARIA DE PRODUÇÃO RURAL E REFORMA AGRÁRIA. Programa leite de Pernambuco. Disponível em: <http://www.producaorural.pe.gov.br/leite/ o_programa.htm>. Acesso em: 11 mar. 2006.

TKAEZ, M.; PEDRASSANI, D.; FEDALTO, L. M.; THIEM, E. M. B. Níveis microbiológicos e físico-químicos do leite in natura de produtores do estado de Santa Catarina. In: CONGRESSOBRASILEIRODEQUALIDADE DOLEITE, 1., 2004, Passo Fundo. Anais... Passo Fundo: [s.n.], 2004. CDROM 